\title{
Clinical Pathology: a multidisciplinary medical specialty
}

\author{
Leila Antonangelo, Maria Elizabeth Mendes, \\ Nilo José Coelho Duarte, Alberto José da Silva Duarte
}

\section{INTRODUCTION}

$\mathrm{T}$ he Clinical Pathology discipline, currently linked to the Department of Pathology, has its focus in assistance, teaching and research activities the Central Laboratory Division (Divisão de Laboratório Central - DLC) and the Medical Research Laboratory (Laboratório de Investigação Médica 03 - LIM 03). The Clinical Laboratory and part of the LIM 03 are located on the 2nd floor of the Building of Ambulatories, occupying an area of appoximately $5000 \mathrm{~m}^{2}$. The laboratory of the Clinical Hospital of the University of Sao Paulo Medical School (Hospital das Clínicas da Faculdade de Medicina da Universidade de São Paulo - HCFMUSP) performs 13 million tests a year and was the first laboratory in the public service to obtain national and international quality certifications.

\section{Past and Present}

In the 30s, the Clinical Pathology was inserted in the $13^{\text {th }}$ discipline headed by Prof. Antonio de Almeida Prado (Internal Medicine, Propaedeutic and Clinical Laboratory), and Prof. Gastão Fleury da Silveira was responsible for the Clinical Pathology discipline. He headed it from April 1932 to March 1950. On this occasion, this discipline was installed in the 1st Men's Medicine ward of Sao Paulo Santa Casa Medical School and the space was shared with the Neurology service. As it did not feature other employees besides the head professor, the laboratory performed a small number of tests, and the biological samples were collected by medical students themselves.

In 1943, Professor Gastão Fleury invited Dr. Octávio Armínio Germek, who had just returned from the USA to help him to set up the Central Laboratory, which was in the final stage of its construction. In the following year, Dr. Germek became the head of the Clinical Biochemistry Laboratory, a part of the Clinical Laboratory, and became an assistant in the Physiological Chemistry Discipline of FMUSP.

However, many difficulties permeated the installation of the Clinical Laboratory. World War II was taking place and importing equipment was almost impossible. The alternative in order to make it viable was the acquisition of second-hand equipments and to make improvised workbenches out of doors supported by sawhorses. This was the way the first urine test was done from a patient of the Emergency Room.

FMUSP's Department of Pathology, Clinical Pathology Subject.

Mailing address: Leila Antonangelo. Av. Dr. Arnaldo $455-1^{\circ}$ andar - sala 1155. São Paulo, SP, Brasil. CEP: 01246-903. Email: 1.antonangelo@hc.fm.usp.br 
With the advances in diagnostic methods and the need to provide support to assistance, teaching, and research as required by the Clinical Hospital, the laboratory was then allocated on the $7^{\text {th }}$ floor of the Central Institute, remaining there until the construction of the Ambulatory building (by the late 70s), where it occupies, to this day, the $2^{\text {nd }}$ floor with an approximate area of $5000 \mathrm{~m}^{2}$, including all the technical areas: Clinical Biochemistry, Hematology, Cytology, Flow Cytometry, Genetics, Microbiology, Molecular Biology, Urgency, Parasitology, Auxiliary Service, Samples collection and Reports Expedition. The laboratory currently performs around 13 million tests per year and features more than 500 employees.

The Clinical Pathology laboratories are traditionally pioneers in technological innovation. This quest is motivated to a great extent by the desire to replace manual operational routines for automated processes, increasing the productivity and analytical quality of laboratory tests and also by the need to incorporate and make available new diagnostic methods in its testing menu. As examples of these facts, we highlight the implementation in 1996 of the Molecular Biology Lab and, more recently, the incorporation of mass spectrometry techniques and next generation sequencing techniques in laboratory practice.

\section{Teaching}

The training of highly qualified human resources has always been a policy of the Central Laboratory Division. An example of this is that in its early days, it created and organized a course for training laboratory technicians. From 1950 on, the courses were replaced with two-year internships in the facilities of the Central Laboratory and, more recently, the specialization course for non-medical professionals was established, also 2-year long and equivalent to Medical Residency.

\section{Medical Education}

The Clinical Pathology discipline, as mentioned previously, has already been linked to numerous clinical disciplines, and remaining for the longest linked to Internal Medicine and Propaedeutics discipline. With the first curricular reform, the Clinical Pathology was absorbed by Propedeutics and Introduction to Medicine discipline, as part of the Internal Medicine Department, with significant reduction of workload and little participation in theoretical classes for the medical graduation course. In the second semester of 1976, the discipline of Clinical Pathology was created at the discretion of the Department of Pathology's Board, and Prof. Germek, the only Professor in Clinical Laboratory, became the head of the Discipline and was transferred to the Department of Pathology in March of 1978. It is noteworthy that, almost 40 years after the creation of the discipline, the position of Full Professor of the Clinical Pathology Discipline appeared in July 2009, and the position for Associate Professor appeared in 2014.

Currently the Clinical Pathology discipline is part of the $4^{\text {th }}$ year of the old medical curriculum and of the $1^{\text {st }}$, $2^{\text {nd }}, 3^{\text {rd }}$ and $4^{\text {th }}$ years of the new curriculum, in the Curricular Unit 21, which is based on Integrated Case Discussion, coordinated by the Internal Medicine, Pathology, Radiology and Clinical Pathology disciplines.

From 2016 on, Clinical Pathology was included in the League of Pathology with fortnightly meetings for each laboratory subject and an integrated meeting with Surgical Pathology per month. It is worth highlighting the great satisfaction of students in participating "on site" in the Clinical Laboratory, being part of and experiencing on its daily routine.

It is also worth highlighting, the participation of the Clinical Pathology in Scientific Initiation program. It is unquestionable that a laboratory that serves 1,500 ambulatory patients a day and performs about 40,000 tests a day represents a never ending source of material for research.

\section{Medical Residency}

The medical residency training began in 1972, with only one position available. From the 80 s on, the number of positions was expanded to 6 a year, on a two-year program of which one would be a basic year in clinical subjects and one dedicated to Clinical Pathology. From 1976 on, a third optional year was added, enabling specialization in a specific laboratory area: Hematology, Clinical Biochemistry, Immunology or Microbiology.

We currently have two positions for entering the specialty, in a regular 3-year long program: 1 year of Internal Medicine and 2 years in Clinical Pathology. Since 2015 we have earned one more position for an 
additional year that can be attended in Oncohematology, Microbiology/Molecular Biology or in Laboratory Quality. The Clinical Laboratory has partnership agreements with specialized international universities such as the National Health Institute (NIH), and the Harvard and Johns Hopkins Universities in the United States, making it possible for residents in training to go on an internship in these renowned centers.

\section{Research}

The Clinical Laboratory participates in institutional research on several fronts. Its clinical staff is composed of 27 physicians, most of whom have a $\mathrm{PhD}$ degree. The doctors have their own research, generally related to their area of expertise. This staff acts as a partner in the clinical trials developed in the various disciplines/Hospital services, providing laboratory tests with the quality required for such research. To date, the DLC's Research Committee has participated as a partner in 980 research projects (with humans and experimental animals), 420 of which are currently active.

The Medical Research Laboratory 03 (Laboratório de Investigação Médica 03 - LIM 03), which belongs to Clinical Pathology discipline, is located on the premises of the Central Laboratory and in a room located at the FMUSP. When the Clinical Laboratory earned the quality certification from the College of American Pathologists (CAP), there was a need for separating laboratory tests performed on animals from those performed on humans. In this way, a complete clinical analysis laboratory, in a multiuser system, was set up inside the School of Medicine, as a branch of the LIM 03, to meet the institutional demand for research with experimental animals.

\section{Perspective}

On its contemporary line, the inauguration of the first stage of the "Core Lab" is planned for this year of 2016. The "Core Lab" is a modern concept of laboratory, which will assimilate in automated sequential platforms the sectors of Clinical Biochemistry, Hormones, Tumor Markers, Hematology, Coagulation, and Serology. This integration will bring the possibility to triple the test production capacity and will optimize both the physical space and human resources. The result of this endeavor will also reflect in the need of collecting fewer tubes of blood from the patients (less physical stress for the patient and a reduction in costs) and a reduction in the time needed to release the tests (TAT), making the diagnosis and/or monitoring of the patients easier, bringing greater efficiency in the clinical practice.

With the diagnostic advances in diagnostic molecular and genetic basis, the Molecular Biology section is in its turn being restructured in order to expand its platform to tests in the areas of Oncology (Haematology and Solid Tumors), Infectious Diseases and Constitutional Diseases.

The other areas have been gaining strength with updated techniques. Microbiology, for example, received two MALDI-TOF mass spectrometry devices, enabling for quick microorganism identification, often in less than two hours.

Thus, we believe that the Central Laboratory Division of the University of Sao Paulo's Clinical Hospital has been growing both in production and quality, without neglecting education of the physicians on the request of tests and their interpretation, avoiding unnecessary requests and economic waste. 